\title{
تمثثلات المجال الأخضر العام في مدينة قسنطينة
}

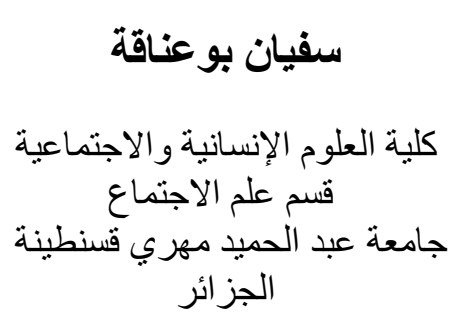

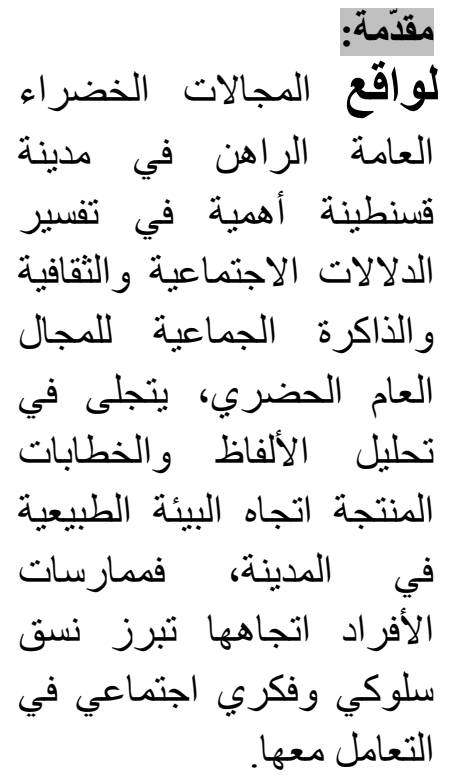

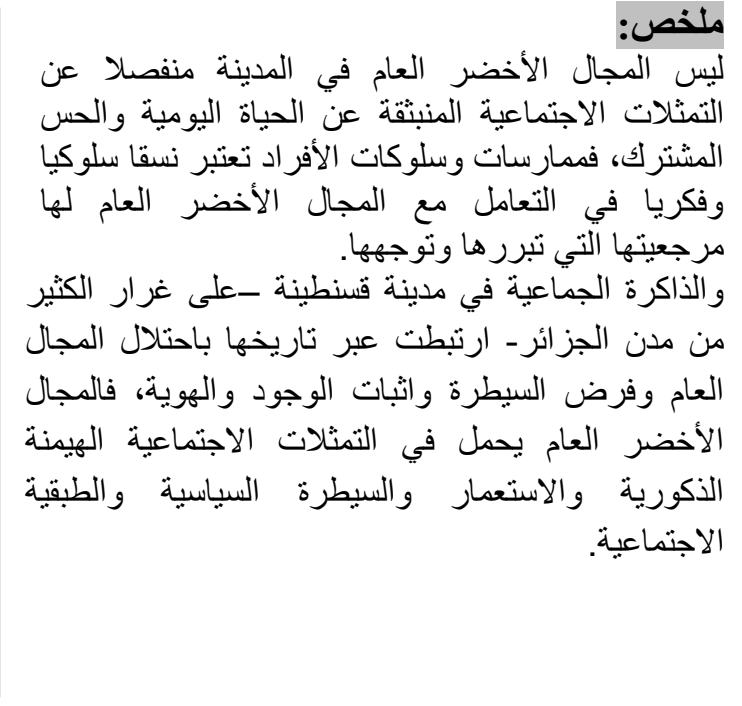

\section{Abstract:}

The public green space is related to the social environment emerging from the daily life, common sense and individual practices and behaviour, which represent the attitude and ideological method in dealing with public green spaces that have a reference which justify and guide it.

The collective memory of the city of Constantine, like many other cities of Algeria, has historically been linked to the occupation of the public spaces, the imposition of control and the proof of existence and identity. The general green domain holds in social manifestations male domination, colonialism, political domination and social class 


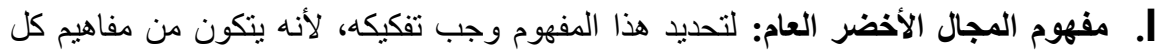

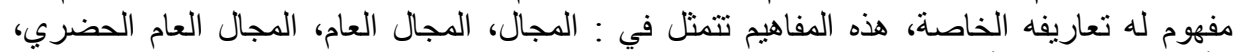

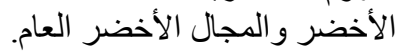

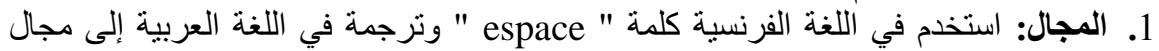

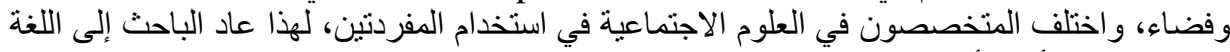
العربية لتقصي أيهما أصح في الترجمة.

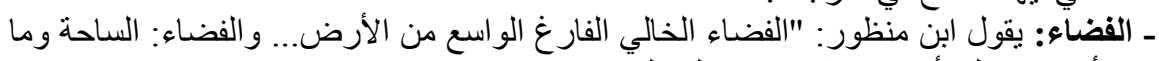

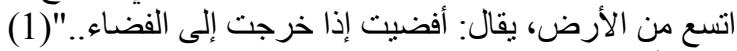

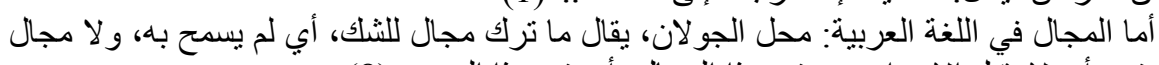

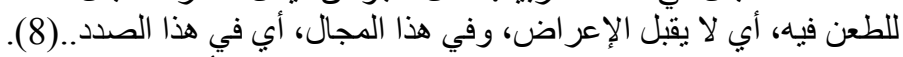

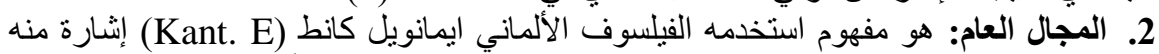
إلى الممارسة الديمقر اطبة ويعتبر يور غن هابرماس ( Habermas. J ) من أعاد استخدامه وتعميمها،

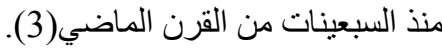

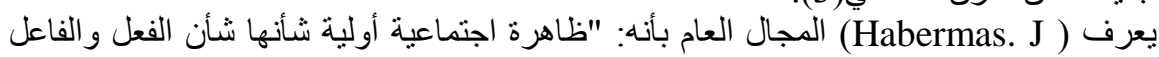

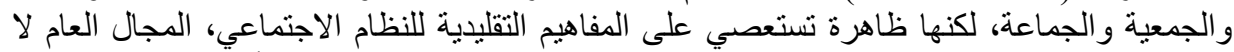

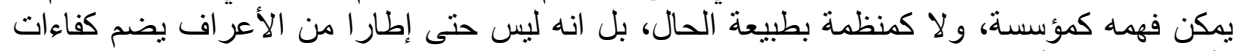

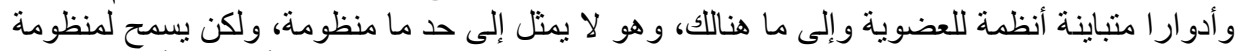

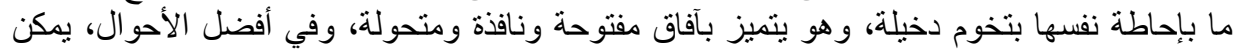

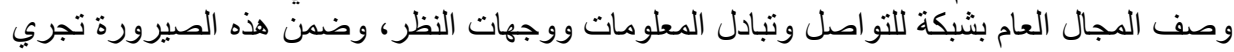

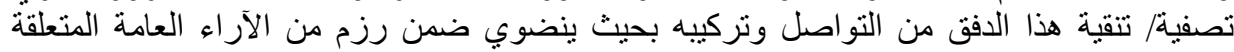

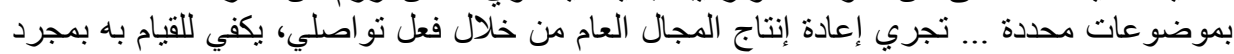
إتقان لغة طبيعية "(9).

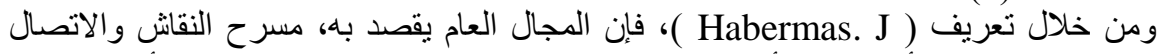

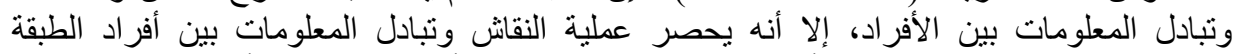

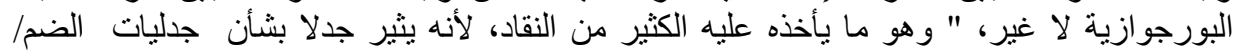

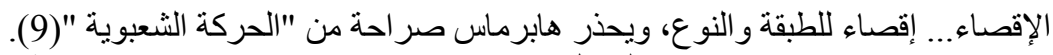

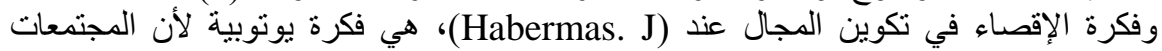

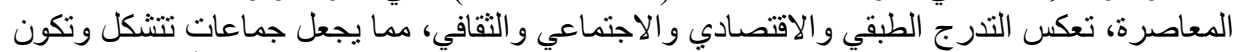

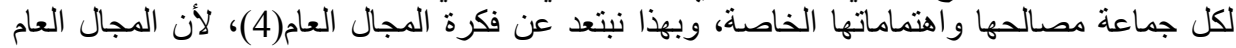

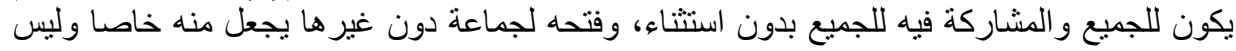
عاما. وفي تعريف آخر غير إقصائي يعرف المجال العام على أنه: " وسيلة من وسائل التعبير

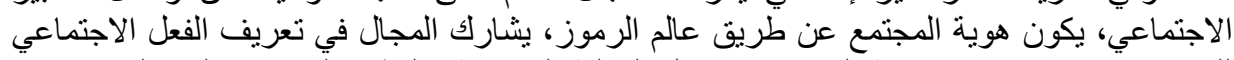

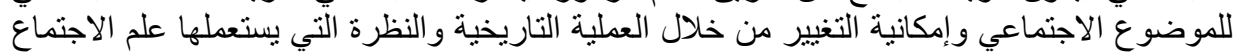

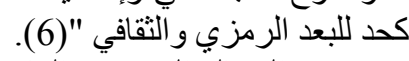

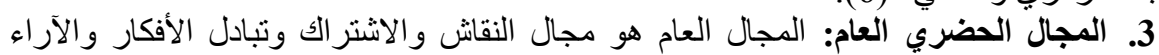

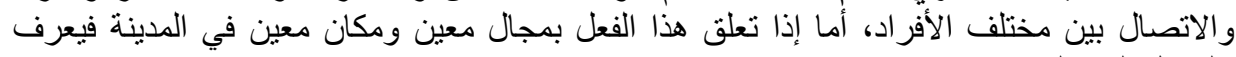

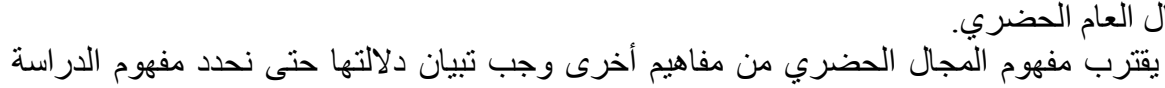




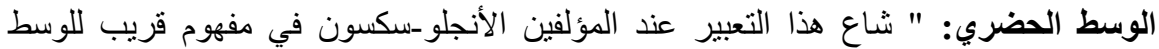

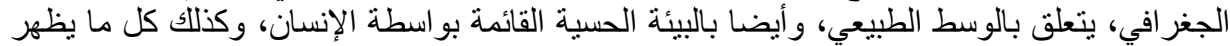

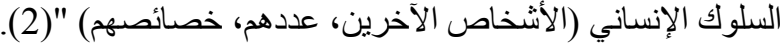

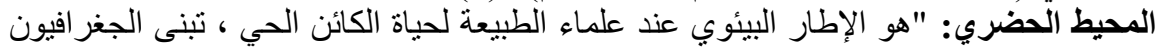

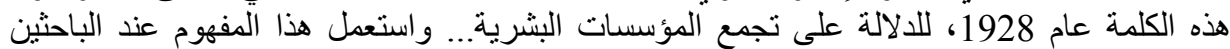

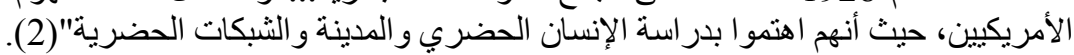

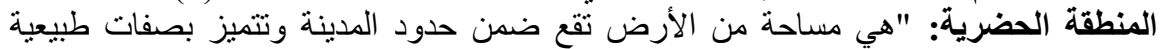

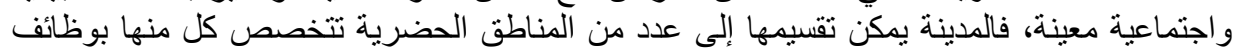

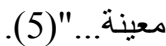

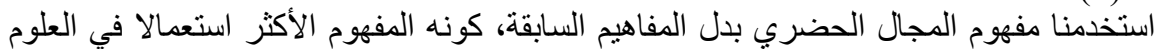

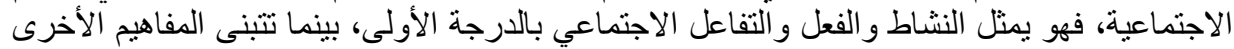

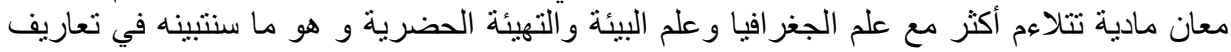
المجال الحضري العام الآتية.

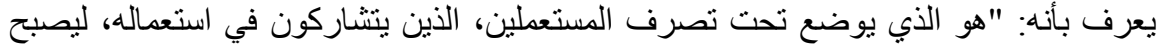

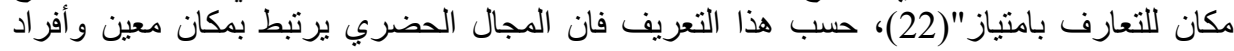
يستعطلونه للتعارف فيما بينهم.

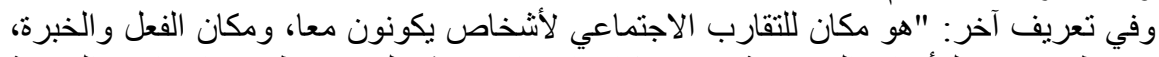

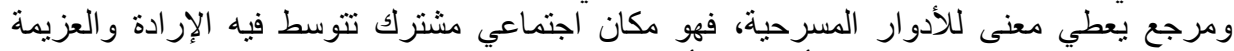

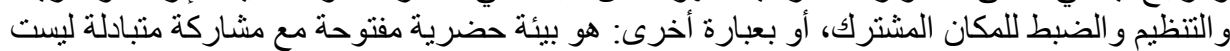

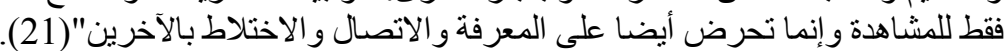

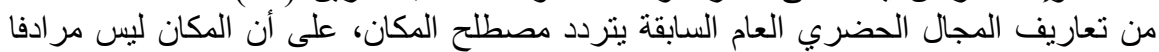

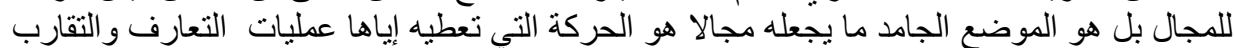

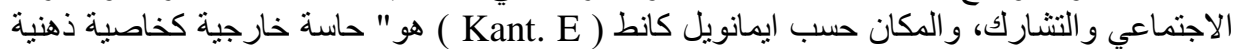

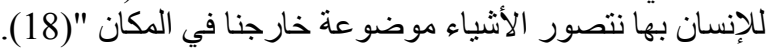

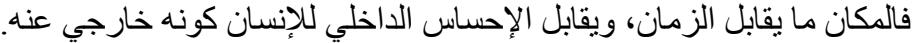

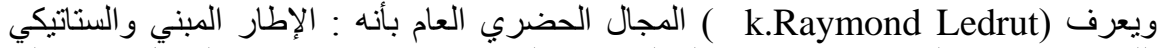

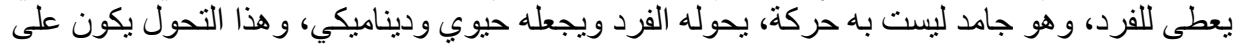

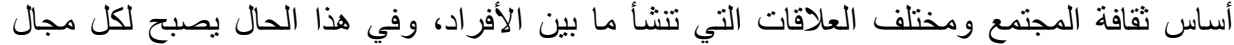
حضري وظيفة معينة تعبر عن العلاقات الاجتماعية "(25).

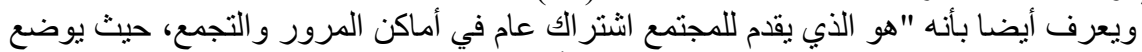

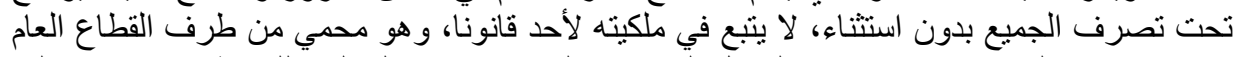

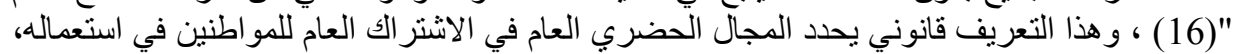

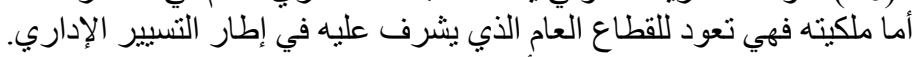

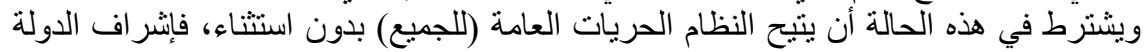

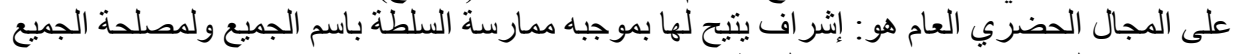

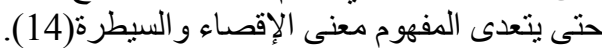

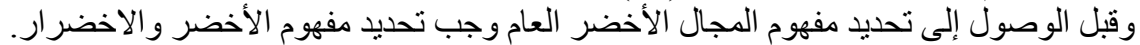

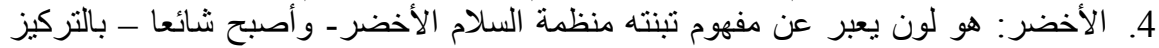

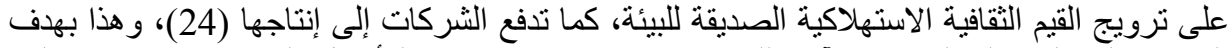

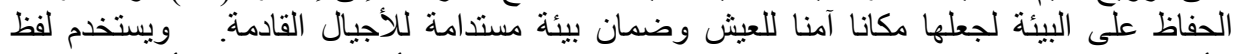

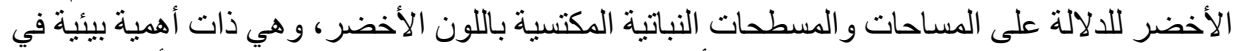
تتقية الهواء والحفاظ على التربة ونوفير الأكسجين وخفض الحرارة... مفهوم المجال الأخضر العام، العالية 
يعتبر حديث نسيا لأنه استخدم أول مرة في القانون المالي التوجيهي الفرنسي سنة 1976، وعرف على على المئ

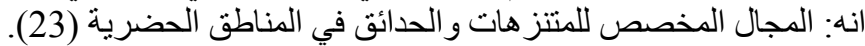

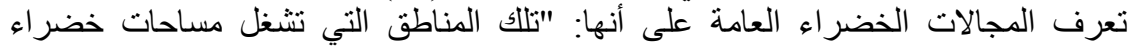

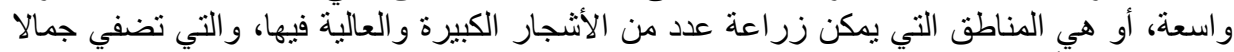

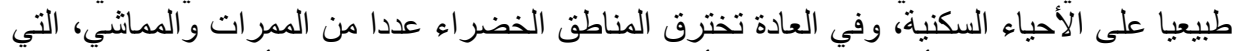

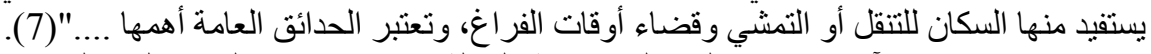

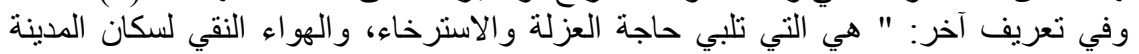
وتجذبهم إلى الطبيعة "(20).

ومما سبق فالمجالات الخضراء العامة، هي المجالات التي تثنظلها الأثجار والنباتات مشكلة

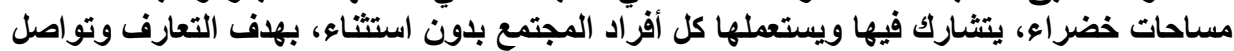

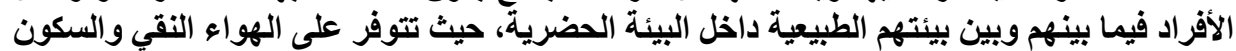

II

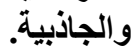

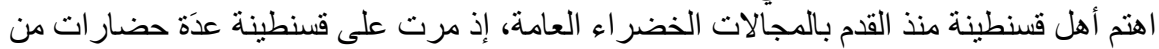

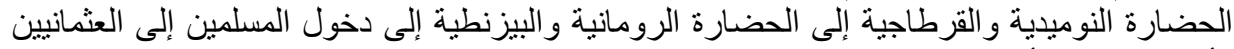

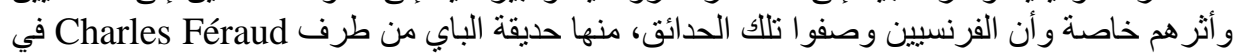

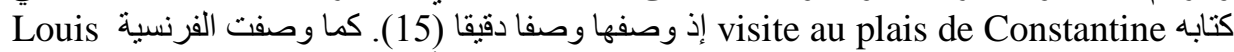

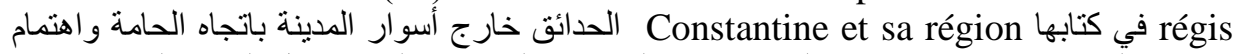

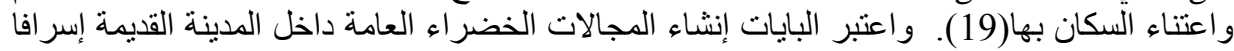

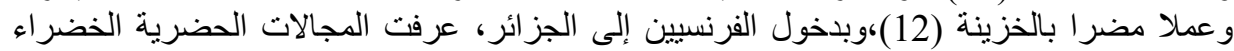

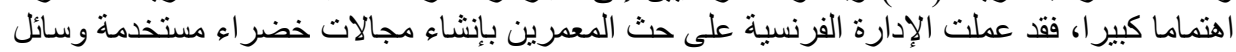

$$
\begin{aligned}
& \text { - المعارض التي تعرض النباتات و الحدائق التجريبية. } \\
& \text { - - - المسابقات المشجعة على خلق الحدائق و البستنة. }
\end{aligned}
$$

- - مثت الجر ائد و المجلات اليومية ووسائل الإعلام المكتوبة المعمرين على إنشاء الحدائق، من

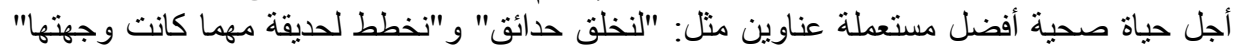
و اكيف يمكن أن نتنزه"...

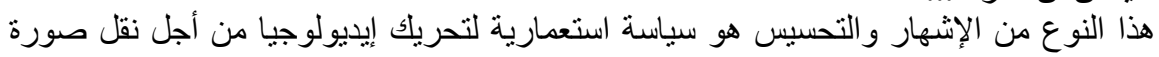

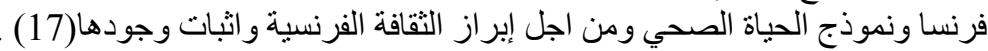

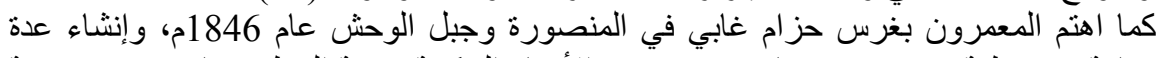

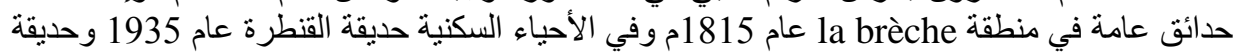

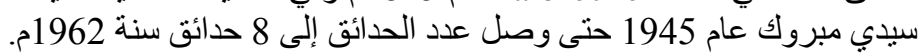

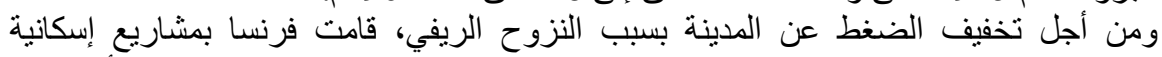

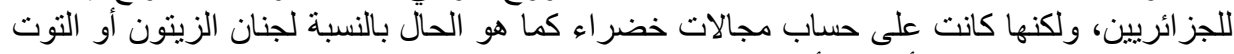

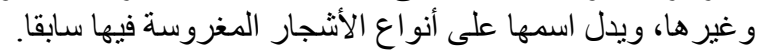

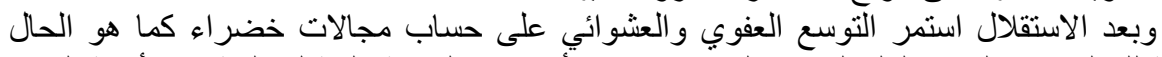

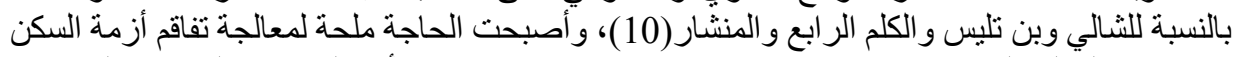

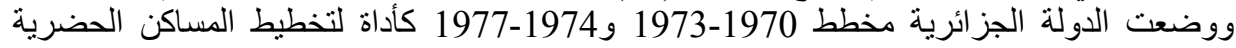

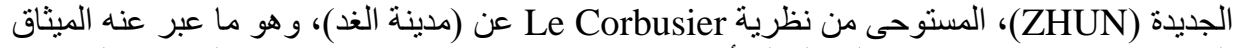

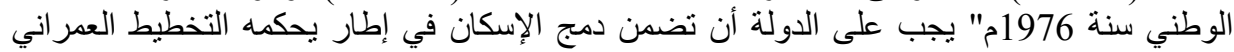

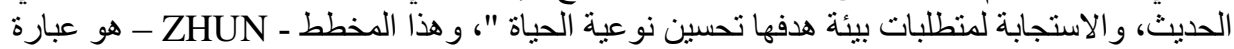

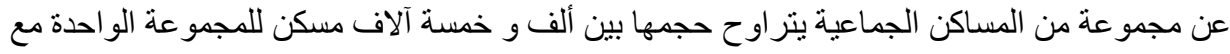


توفير المر افق الضرورية بما فيها المجالات الخضراء العامة، شرع في هذا المخطط ابتداء من سنة

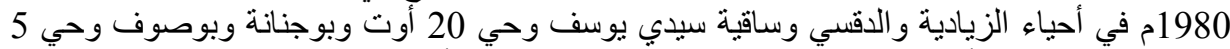

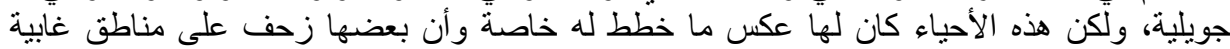

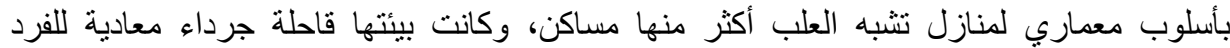

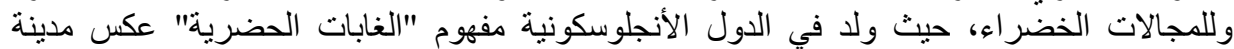

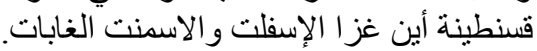

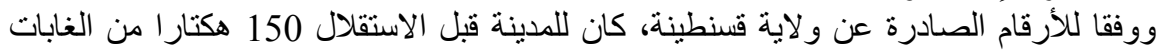

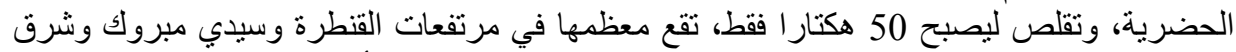

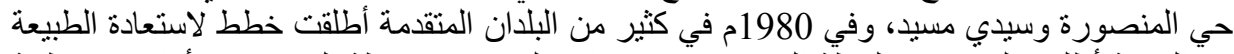

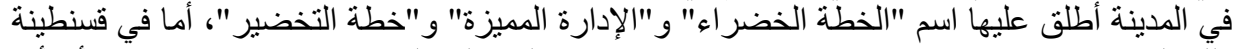

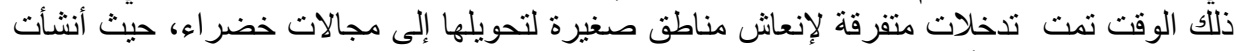

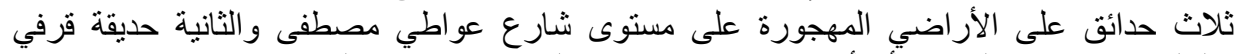

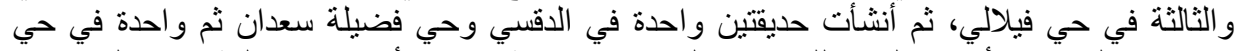

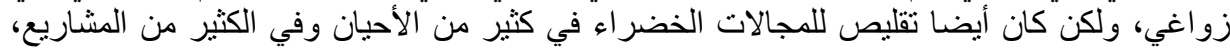

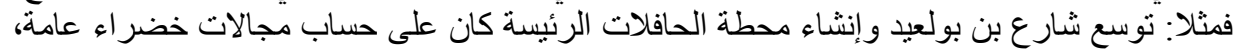

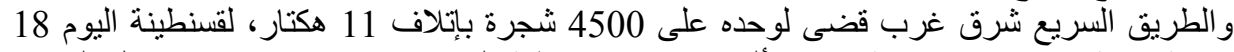

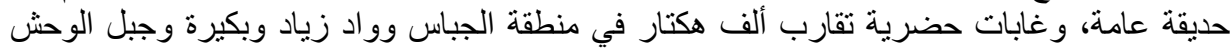

المعايير الكمية في توزيع المجالات الخضراء على أحياء ملئ مدينة قسنطينة:

و المريج(13).

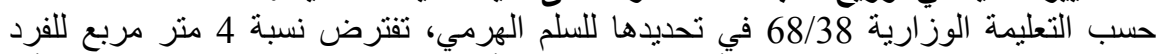

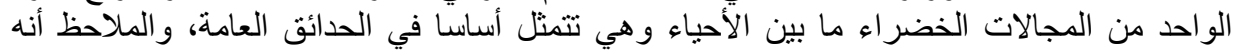

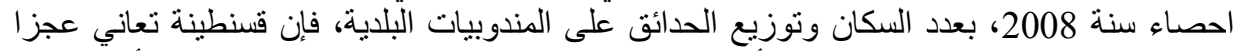

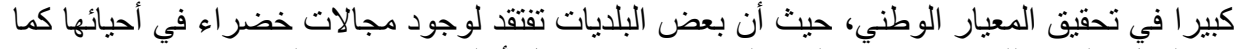

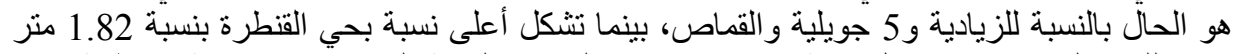

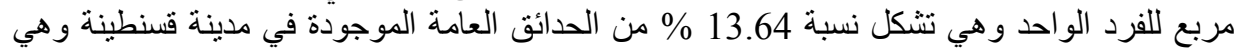

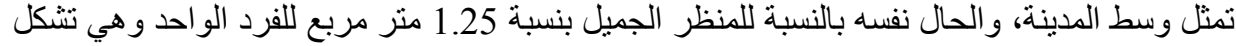

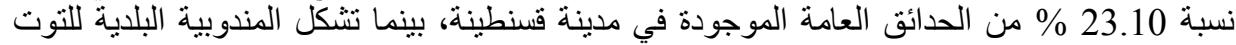

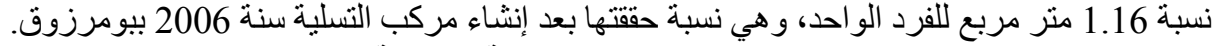

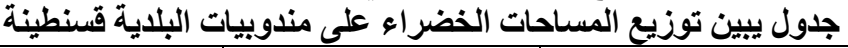

\begin{tabular}{|c|c|c|c|}
\hline النسبة ( م2 / للفرد) & إحصاء سنة 2008 & الحدائق العامة (م2) & المندوبية البلاية \\
\hline 0.56 & 51078 & 28500 & سيدي راشد \\
\hline 1.25 & 43043 & 54000 & المنظر الجميل \\
\hline 1.82 & 29554 & 53700 & القتطرة \\
\hline 0.49 & 64648 & 31700 & سيدي مبروك \\
\hline 00 & 46014 & 1 & القماص \\
\hline 1.16 & 60360 & 70000 & التوت \\
\hline 0.13 & 47966 & 6100 & بودراع صالح \\
\hline 00 & 44244 & 1 & الزيادية \\
\hline 00 & 31765 & 7 & 05 جويلية \\
\hline 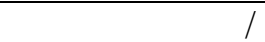 & 418672 & 162800 & المجموع: \\
\hline
\end{tabular}

المصدر: جدول مركب، الديوان الوطني للإحصاء 
ـ البايلك: و هو تعبير ومسمى مثتق من اسم "الباي" وهو الحاكم الممثل للسلطة العثمانية، الآمر

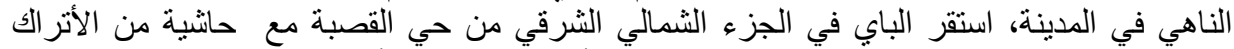

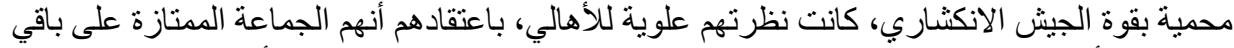

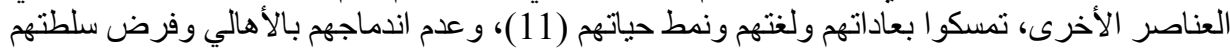

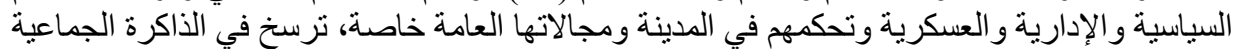

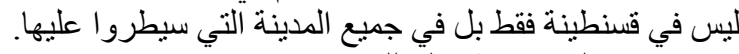

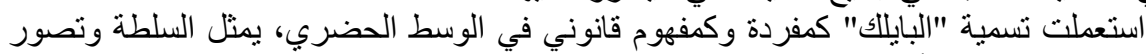

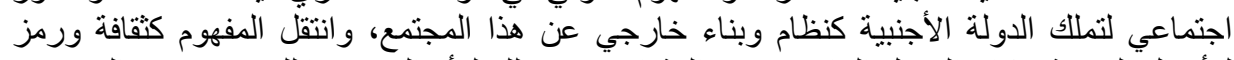

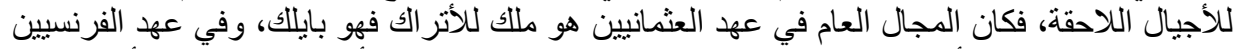

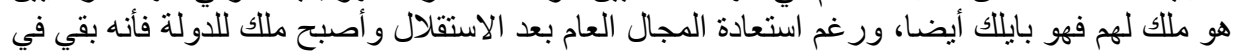

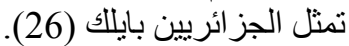

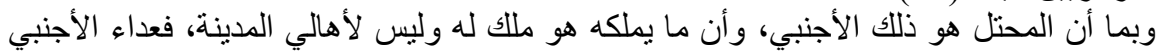

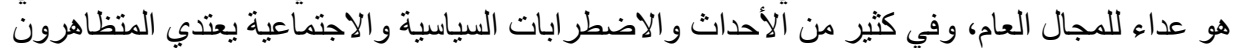

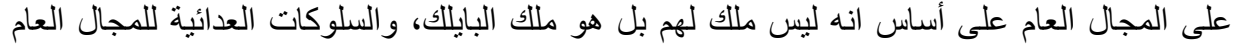
تظهر في الحياة اليومية فرمي الأوساخ وتكسير المقاعد ومختلف المرافق هو مرتبط بشكل أو آخر بهذال الئا التصور ولو كان خاطئا.

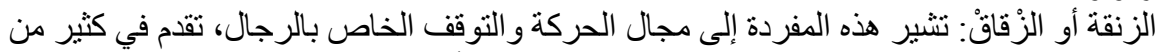

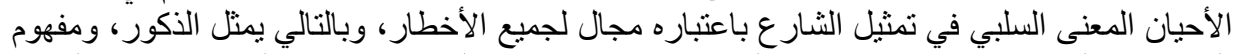

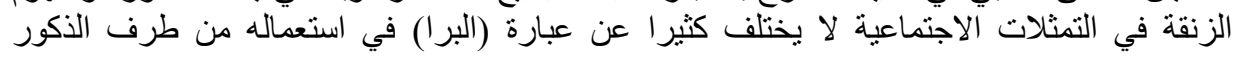

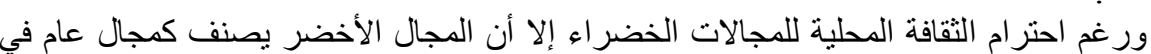
و واستباحته في

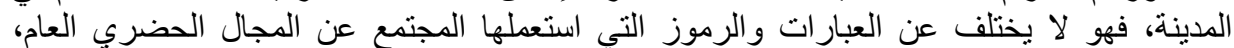

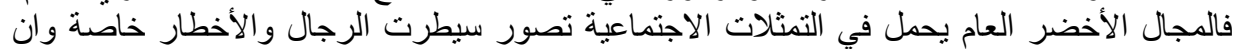

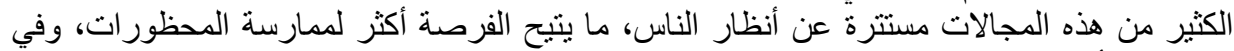

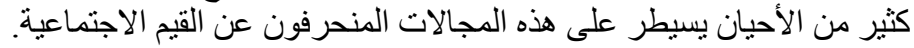

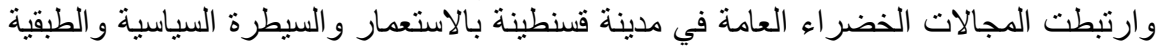

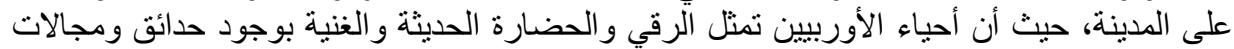

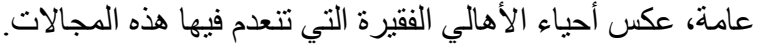

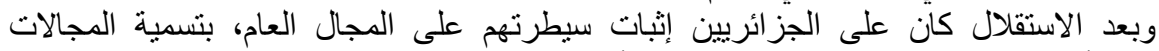

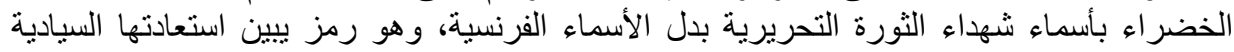

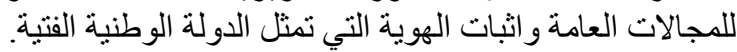

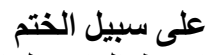

ارتبط الواقع الراهن للمجالات الخضر الواء العامة في مدينة قسنطينة بالذاكرة الجامعية المرتبطة

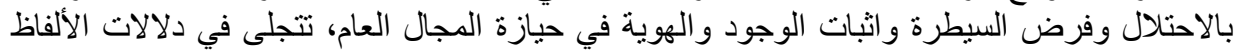

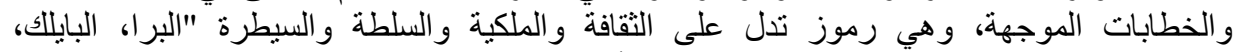

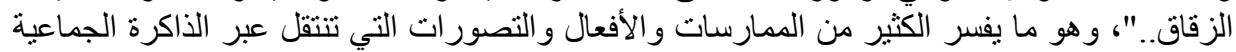

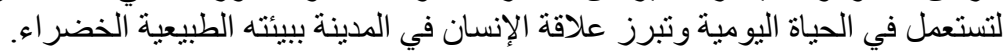
المراجع

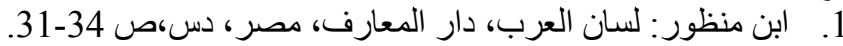

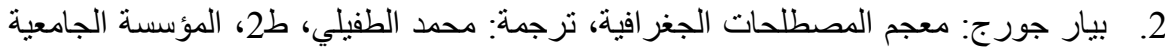
للار اسات و النشر والتوزيع، لبنان، 2002. 
3. حسن مصدق: يورغن هابرماس ومدرسة فر انكفورت, النظرية النقدية التواصلية، المركز النقافي للكتاب، لبنان،

4. خلد كاظم أبودوح: مفهوم المجال العام, الأبعاد النظرية والتطبيقات، مجلة إضافات (مجلة

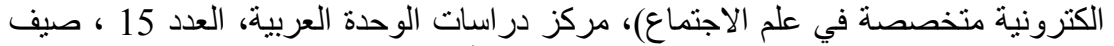

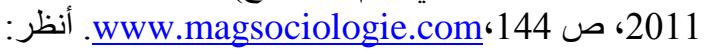

(Parkins. Jhon : forest Management and Advisory groups in Alberta : An Empirical Critique of Emergent public sphere, Canadian Journal of sociology, ).vol 27, $\mathrm{N}^{\circ} 2$ ? Spring, p169

5. ديكن مينتيل: معجم علم الاجتماع، ترجمة: إحسان محمد حسن، دار الطليعة للطباعة و النشر، بيروت، لبنان، 1981. 6. عبد الحميد دليمي: الو اقع و الظو اهر الحضرية، منشور ات جامعة منتوري، قسنطينة، دس. 7. عبد الرزاق عباس حسين: جغر افية المدن، مطبعة اسعد، بغداد، 1977.

8.

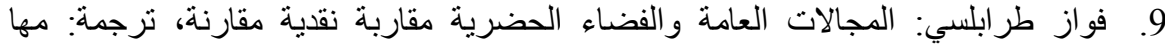

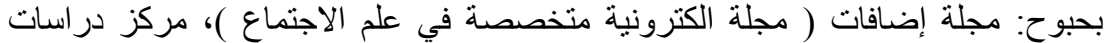

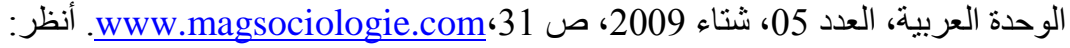

-Habermas. Jürgen: Between Facts and Norms: Contributions to a Discourse Theory of Law and Democracy, Cambridge, MA : MIT Press ( Studies in Contemporary German Social Thought,1996).

$$
\begin{aligned}
& \text { 10. محمد الهادي لعروق وآخرون: البيئة في الجزائر, التأثير على الأوساط الطبيعية }
\end{aligned}
$$

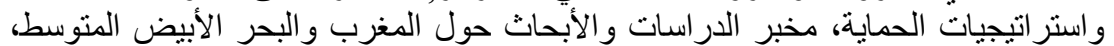

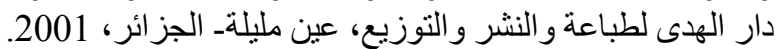

$$
\begin{aligned}
& \text { 11. محمد بن علي شعيب: قسنطينة أم الحو اضر في الماضي و الحاضر، مطبعة البعث، قسنطينة، } \\
& \text { 1980 } \\
& \text { 12. ناصر الدين سعيدوني: دراسات وأبحاث في تاريخ الجزائر, الفترة الحديثة والمعاصرة، }
\end{aligned}
$$

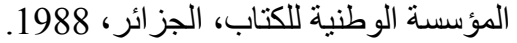

ALI-KHODJA ADRA: espace vert public urbain de l'historicisme a la .13 normativité ( cas de Constantine ), thèse de doctorat es-science option urbanisme ; faculté de la terre de la géographie et de la ménagement du territoire; département d'architecture et d'urbanisme, université de Constantine ,13/07/ 2011.

Bayhoun Nabil et Jean Claude Davide : Du Souk à la place du citadin .14 au citoyen ; Ecpace Public dans les villes arabes ( au moyen orient ), science sociales et phénomènes urbains, fondation ibensaoud, Casablanca.

Charles Féraud : visite au plais de Constantine, nouveau journal des .15 voyages, librairie hachette et Cie, paris, 1877.

Espace public européen : histoire et méthodologie European public .16 spaces: history and methodology; Colloque international Paris, 9-10 octobre 2014 - 9-10 October 2014 
ikram saidane: le concept des jardins de l'époque coloniale en .17

Tunisie ; entre importation et culturation, acte de séminaire, étape de recherches en paysage, $\mathrm{n}^{\circ} 7$, école nationale supérieure du paysage, Versailles, 2005, pp 74-76. www.varssaille,écol-payasage.fr Kant Emmanuel : Critique de la Raison Pur, Ed Flammarion, France, . 18 1987.

louis régis : voyage et séjours (Constantine et sa région), introduction .19 de a. Mézières de l'académie française, éditeur ancienne maison .Michel Lévy frères. A la librairie nouvelle, paris, 1880

Muret. J. p et autres : Les espaces Urbains, ED du Moniteur, paris, .20 1987.

Nathalie Bouvier et Daclon Gilles Sénécal : les jardins communautaires .21 de Montréal, un espace social ambigu, revue loisir et société, volume 24, $\mathrm{N}^{\circ} 2$, presse de l'université du Québec, automne 2001.

Pierre Merlin et François Choay: Dictionnaire de L'urbanisme et de .22 L'ménagement, PUF, paris ; 1988.

Plane .A : La commune et L'aménagement Des sites, ISBN, paris, .23 1980.

Pride .w et Ferrel .o. c : Marketing Concepts et Stratégies,3rd, Ed .24 Mifflin, New York, 2003.

Raymond Ledrut : L'espace en question ou le nouveau monde urbaine, .25 Ed Anthropos, paris, 1976.

Nassima dris: la ville mouvementée (espace public, centralité, .26 mémoire urbaine à Alger), éd. Harmattan, paris, 2001. 